\title{
Second Language Teaching and Teacher Education in Diverse Contexts
}

\author{
Bui Phu Hung ${ }^{1}$, Tatiana A. Baranovskaya ${ }^{2}$ \\ ${ }^{1}$ University of Economics Ho Chi Minh City \\ ${ }^{2}$ National Research University Higher School of Economics \\ Correspondence concerning this article should be addressed to Bui Phu Hung, University of Economics Ho \\ Chi Minh City, 59C, Nguyen Dinh Chieu Street, Ho Chi Minh City, Vietnam. \\ E-mail: buiphuhung@yahoo.com
}

\section{Introduction}

Second language teaching and learning research shows some topics of remaining interest to researchers and practitioners. Class performances have been uninterruptedly explored, although a vast amount of research on language pedagogy and applied linguistics have suggested particular implications for second language (L2) education. The concept that a pedagogical approach can fit all contexts is no longer valid. The student-centered approach has inspired investigations into learners' needs, beliefs, and performances and provided evidence that learning outcomes sometimes do not meet teachers' and learners' expectations. Learner variables and contextual factors are included in research testing established hypotheses and investigating arising problems, such as technology-mediated learning and emergency teaching due to the outbreak of Covid-19.

Stapleton (2013) gathered data submitted to a conference hosted by The Japan Association for Language Teaching for three decades and identified some research interests in the field of language teaching. Language Skills and Classroom Content (including English for specific purposes) remained the most strands, followed by Teacher Education. Classroom Pedagogy also received more researchers' attention. There was a growing research interest in The Socio-Cultural Theory, Vocabulary, Motivation, and Second Language Acquisition. This made Paul Nation, Lev Vygotsky, Zoltan Dornyei, and Rod Ellis become four of the most cited scholars in the field. The number of teacher-researchers as L2 speakers increased significantly. However, Grammar received less researchers' attention. A comparison with submissions to some other conferences in the field showed some overlaps of arising trends.

This special issue consists of eleven articles reporting contextualized research on various topics. The first eight articles aim to improve language teaching and learning effectiveness by investigating teachers' and learners' beliefs and learning outcomes from educational interventions. The last three articles report research on teacher-related concerns with implications for L2 pedagogy and teacher development.

\section{The Focus of This Special Issue}

Kaspul Anwar, M. Faruq Ubaidillah, and Urip Sulistiyo examined L2 teachers' use of classroom management techniques in secondary schools in rural settings in Indonesia. They argue that L2 teachers should employ appropriate classroom management techniques to create a learning environment, which helps students achieve the expected goals. The findings showed both local and global problems. The authors also argue for the improvement of the L2 learning environment and teachers' professional development.

Otmane Omari, Mohammed Moubtassime, and Driss Ridouani investigated 365 undergraduate students' beliefs of self-efficacy at three Moroccan universities. Self-efficacy or self-confidence to perform a specific task well. A breakdown of students' responses to a questionnaire in a Likert-scale of 1-5 showed the students' moderate level of self-efficacy. Also, the junior students demonstrated a higher level of self-efficacy than the sophomore students. The evidence showed the impacts of the social contexts and learners' initial motives on their self- 
efficacy beliefs. The authors argue for the improvement of Moroccan students' self-efficacy to increase their academic achievements.

Flora Komlosi-Ferdinand investigated students' attitudes and social-emotional responses to local and foreign teachers in Mongolian bilingual schools. The results showed that the local students showed more respect and discipline with the local teachers than foreign teachers. A factor responsible for such discrimination was cultural identity partly because the local teachers were aware of the values in Mongolian culture. However, the students considered the foreign teachers friendlier and more outgoing. Also, social and behavioral development constituted the students' attitudes because they could communicate with the local teachers better in their native language. In other words, sharing a common language was another factor in making people understand, which, in turn, form community ties.

Faisal Mustafa, Usman Kasim, and Asnawi Muslem were inspired by learner-centered education and explored the effectiveness of intervention of learning by teaching. Learning by teaching is believed to improve students' active learning. This study employed pretest-posttest between-group design and involved 46 Indonesian EFL university students: 22 students in the experimental group and 24 students in the control group. The students involved in the experimental group were required to have group discussions before they performed their teaching, but the control group received the teacher-led instruction. The data analyses showed that there was no significant difference in the posttest scores of the two groups. One underlying reason for such an insignificant difference was that learning by teaching needs adequacy of time to help learners master the content they teach. Besides, the participants' low proficiency level was a barrier to their understanding of the materials they were assigned to teach. However, interestingly, the students who learned by teaching demonstrated a significant growth of their teamwork skills.

In the sixth article of this special issue, Ana Cecilia Villarreal Ballesteros, Irlanda Olave Moreno, and Lizette Drusila Flores Delgado provide an interesting idea that uses conceptual metaphors used by pre-service teachers in reflections of their pedagogical beliefs. The conceptual metaphors, or cognitive metaphors, which one uses show the mental representations of information across domains. The researchers collected and analyzed data from texts written by $42 \mathrm{~L} 2$ teacher students. The results showed that conceptual metaphors used by the preservice teachers did not reflect contemporary literature in L2 pedagogy although the input they received from their professors and materials provided updated perspectives on L2 pedagogy. The teacher's practice reflects both the theories that they have learned and their realities.

Rastislav Metruk introduces a concept of defining a good and effective L2 teacher. This article compares the discrepancies in Slovak pre-service and in-service secondary L2 teachers' beliefs of the attributes of a good and effective teacher. The participants most highly agreed that six important attributes of an L2 teacher were about the teacher's roles both inside and outside the classroom. The differences in the pre-service and in-service teachers' ratings mainly reflected their professional background. The author argues for the most critical categories which make up a good and effective L2 teacher: 1. being aware learner differences, 2 . having appropriate L2 pedagogy, 3. encouraging learner autonomy, 4. having good classroom management strategies, and 5. being good-looking.

The practice of student evaluation of teaching has been an increasing interest in the last decades. Students' constructive evaluations are deemed to improve the quality of teaching and learning. Different cultures take different views of this practice. Irina S. Morozova, Aleksey A. Chusovlyankin, Elena A. Smolianina, and Tatyana M. Permyakova qualitatively investigated how Russian-speaking students evaluated the quality of L2 teaching at National Research University Higher School of Economics, Russia. These researchers applied the natural semantic metalanguage theory to analyzing the students' feedback. The students' ratings showed they more highly evaluated the elements closely associated with the teacher. These researchers argue that the teacher is a crucial part of effective L2 teaching.

In many contexts, female teachers' professional development is restricted although they make up a large proportion of the labor force in education. The distinct characteristics of effective L2 teachers and teaching show requirements for L2 teachers than those in other fields. Khloud Al-Bdeerat, Basil Alqarraleh, and Abdel Rahman M. Altakhaineh introduce an interesting empirical study on academic challenges confronting female L2 teachers. The researchers collected quantitative data from female L2 teachers in Jordanian secondary 
schools. The results showed that female L2 teachers in Jordan encountered more challenges from students and the community than the other observed factors. The authors argue that cultural values were partly responsible for such challenges.

English as lingua franca (ELF) has inspired a vast amount of research on ELF-associated problems. Communication problems are potential among L2 speakers. Thomas A. Beavitt and Natalia G. Popova investigated Russian scientists' use of English articles in their submissions for publication in international journals. The results showed that the wrong choice and omission of English articles led to semantic and structural problems at the phrase and sentence levels. This article provides implications for L2 education and text analysis.

Research on L2 education has been increasing more than ever in the last decades, with L2 researchers' contributions. However, some arising concern is about the ethical issues which the researchers have considered in their studies. Training L2 teachers in ethical codes is overlooked in some contexts. The last article arouses awareness of ethical issues in L2 education research. Farideh Samadi, Khalil Motallebzadeh, Hamid Ashraf, and Gholam Hassan Khajavy aim to explore 272 Iranian L2 teachers' awareness of ethical issues. The authors argue for the development and introduction of ethical guidance in L2 teacher education programs. The authors call for immediate action associated with research ethics in the Iranian context.

The articles in this special issue report quantitative and qualitative research on various topics conducted in different contexts. They can provide thought-provoking questions. They may motivate further investigations in L2 education and consider Journal of Language and Education a venue to share their empirical studies.

\section{References}

Stapleton, P. (2013). Using conference submission data to uncover broad trends in language teaching: A case study of one conference over 30 years. Language Teaching Research, 17(2), 1-20. https://doi. org/10.1177/1362168812460808 